\title{
Experimental Study on Nanofluid Flow in a Porous Cylinder: Viscosity, Permeability and Inertial Factor
}

\author{
Antonio F. Miguel \\ Department of Physics, Evora University, Rua Romão Ramalho 59, 7000-671 Evora, Portugal \\ Geophysics Center of Evora (CGE), PO Box 84, 7002-554 Evora, Portugal \\ afm@uevora.pt
}

Keywords: $\mathrm{Al}_{2} \mathrm{O}_{3}$ nanofluid, viscosity, nanofluid flow, porous media, non-Darcy flow, hydraulic permeability, intrinsic permeability, inertial parameter, Darcy-Forchheimer equation.

\begin{abstract}
Knowledge of fluid rheology and flow characteristics is important when studying nanofluid flow in porous media. In this study, an experimental investigation is presented to determine the nanofluid viscosity, the permeability and the inertial (non-Darcy) parameter of a porous cylinder made of several capillary tubes. The applicability of the Darcy-Forchheimer equation for power-law fluids to estimate pressure drop through the porous material is discussed. The occurrence of particle losses from the base fluid (deposition) is also verified.

Experiments are completed in two steps. In the first step, physical properties of nanofluids consisting of deionized water and different volume concentrations of $\mathrm{Al}_{2} \mathrm{O}_{3}$ nanoparticles is measured. In the second step, $\mathrm{Al}_{2} \mathrm{O}_{3}$-deionized water nanofluids are pumped through a porous cylinder (porosity 0.249) to evaluate hydraulic and intrinsic permeabilities, and the inertial parameter. The effect of $\mathrm{Al}_{2} \mathrm{O}_{3}$ volume fraction on these flow properties is studied, and the void morphology changes within the porous cylinder via deposition of nanoparticles are analyzed.
\end{abstract}

\section{Introduction}

Trend towards miniaturization and nanotechnology lead to the emergence of nanofluids [1]. Nanofluids are solid suspensions of nanometer-size particles in a base liquid (particles of $100 \mathrm{~nm}$ and smaller, usually with volumetric concentrations less than 10\%) and find important applications in biomedicine, heat transfer, polymers, etc. [2-5].

The strengths of nanofluids have been appraised in the last decades [1-5]. The relatively small thermal conductivity/diffusivity of conventional fluids limits the heat transfer in important processes of fundamental importance in many engineering and industrial applications. Nanofluids have enhanced physical properties such as the viscosity and thermal conductivity/diffusivity compared with those of base liquids [6] and may constitute a viable alternative.

An important factor to consider in the application of nanofluids is their rheology. Fluid flow (e.g., pressure drop, pumping power) and convective heat transfer depend on the fluid viscosity and density. For very small nanoparticle volume fractions, nanofluids seems that can be treated as a Newtonian fluid [7,8]. Increasing of nanoparticle volume fraction starts a shear-thinning/thickening behavior, and makes it more and more remarkable. For $\mathrm{Al}_{2} \mathrm{O}_{3}$-water and $\mathrm{TiO}_{2}$-water nanofluids experimental investigations suggest that a remarkable shear-thinning behavior is observed to emerge at $3-5 \%$ and at $10-12 \%$ nanoparticles volume fraction, respectively [9]. This shear-thinning behavior can be approached by a power-law with an exponent less than the unity. In recent years, numerous studies have been carried out to investigate the influence of particle size and concentration on thermophysical properties of nanofluids and on their heat and mass transfer enhancement [6-13].

Nanofluid flow in porous media is gaining a lot of attention because its applications in geophysics [14,15], pebble-bed nuclear reactors [14,16], catalytic reactors $[14,17]$, food processing [18], heat exchange (porous structures with high thermal conductivity (metal foam) to substitute fins $[12,14]$ ), etc.. Nanofluid flow and heat transfer in the porous media is studied experimentally, analytically and numerically (see for example [19-22]). While these and other important studies, to 
the best knowledge of authors, there are very limited studies on the effect of nanoparticles concentration on permeability and, particularly, on inertia coefficient (non-Darcy regime) of porous media.

In this study, nanofluids are prepared by dispersion of $\mathrm{Al}_{2} \mathrm{O}_{3}$ nanoparticles in water, and their physics properties (viscosity and density) are measured. Then, nanofluid is forced through a porous cylinder. The pressure drop through the cylinder is measured over a range of flow rates and $\mathrm{Al}_{2} \mathrm{O}_{3}-$ water concentrations. Permeability is obtained by using Darcy's law and the inertia coefficient from the nonlinear term of Darcy-Forchheimer equation. These results are compared with these obtained for pure water flowing through the porous cylinder.

\section{Theory}

Fluid Flow and Pressure Drop. There is a class of non-Newtonian fluids that the relationship between shear stress, $\tau$, and shear rate, $\gamma$, is given by $\tau=\mathrm{M} \gamma^{\mathrm{n}}$ and their apparent viscosity, $\mu^{*}$, can be expressed by

$$
\mu^{*}=\mathrm{M} \gamma^{\mathrm{n}-1}
$$

where the fluid behavior index, $\mathrm{n}$, and the consistency index, $\mathrm{M}$, can be determined from experimental measurements. If $\mathrm{n}<1$ the fluid exhibits shear-thinning properties (pseudoplastic behavior) whereas if $n>1$ the fluid shows shear-thickening behavior. For $n=1$ the relation between the shear stress and shear rate becomes the constitutive equation of Newtonian fluids. As mentioned, authors [23-26] suggest that nanofluids exhibit a non-Newtonian behavior $(n \neq 1)$.

Darcy flow in porous media occurs if the Reynolds number is small enough so that there is a linear relationship between fluid velocity and pressure drop [27]. For flow of power-law fluids, we may write [28]

$$
\nabla \Phi=-\frac{\mu^{*}}{\mathrm{k}} \mathrm{u}
$$

with

$$
\Phi=\rho_{\mathrm{n}} \int_{\mathrm{p}_{0}}^{\mathrm{p}} \frac{1}{\rho_{(\mathrm{p})}^{*}} \mathrm{dp}
$$

where $u$ is the superficial velocity, $\rho^{*}$ is the apparent density, $p$ is the pressure and $\Phi$ is the driving potential. Here $\mathrm{k}$ is the intrinsic permeability [27-31] and defines the ability of the porous medium to transmit fluid through it, or the surface area that is open to flow.

Non-Newtonian viscosity changes with the pore velocity, $u_{p}$ (i.e., $u_{p}=u / \varepsilon$, where $\varepsilon$ is the porosity) and therefore according with the flow driving potential. For a flow of a power-law fluid the apparent viscosity can be expressed as

$$
\mu^{*}=\mu_{\mathrm{ef}}\left(\frac{\mathrm{k}}{\mu_{\mathrm{ef}}} \nabla \Phi\right)^{(\mathrm{n}-1) \mathrm{n}}
$$

where $\mathrm{n}$ is the fluid behavior index.

In spite of great applicability of Darcy law, at sufficiently high Reynolds number, the flow is well approximated by a nonlinear approach (Darcy-Forchheimer equation). Shenoy [32] presented theoretical arguments to suggest that the non-linear term of Darcy-Forchheimer equation is not dependent of power law index $\mathrm{n}$ of non-Newtonian fluids. Therefore, the relationship between fluid velocity and pressure can be expressed as [29] 


$$
\nabla p=\left(\frac{\mu^{*}}{k} u^{n-1}+\frac{\rho \beta}{k^{1 / 2}} u\right) u
$$

where $\beta$ is a inertial parameter, $\rho$ is the fluid density, and $\mathrm{k} / \mu^{*}(=\mathrm{K})$ is the hydraulic permeability.

Permeability and inertial parameter can be calculated from experimental data, plotting the pressure drop versus velocity data.

Viscosity and Volume Fraction of Nanoparticles. In 1906, Albert Einstein [33] suggested that for a fluid containing spherical particles in suspension, the relationship between viscosity and the volume fraction of particles $\theta(\theta<4 \%)$ is given by

$$
\frac{\mu_{\mathrm{f}}}{\mu_{0}}=1+0.25 \theta
$$

Here $\mu_{\mathrm{f}}$ is the viscosity of nanofluid and $\mu_{0}$ is the viscosity of the base fluid. Equation (6) was modified and extended by several authors (see for example [34-39]). Nevertheless, despite the existence of important models, some studies report that differences may be found between these models and measured viscosities [40,41]. Empirical correlations are also available in the literature which could be used to obtain the viscosity of a specific type of nanofluid under a specific range of volume fractions (see for example $[42,43]$ ).

\section{Experiments and Methods}

Preparation and Characterization of the Nanofluid. Basically, there are two fundamental methods to obtain nanofluids namely the so-called single-step method (i.e., dispersion of nanoparticles is obtained by direct evaporation of metallic nanoparticles and their condensation in a base liquid) and the two-steps method (i.e., nanoparticles are first obtained and then dispersed into a liquid) $[41,44]$. Here, nanofluids are obtained by dispersing alumina nanoparticles in water (i.e., the two-steps method).

$\mathrm{Al}_{2} \mathrm{O}_{3}$ nanoparticles of density $3.75 \mathrm{~g} / \mathrm{cm}^{3}$ and average size of $40 \mathrm{~nm}$ (Inframat) are used to obtain $\mathrm{Al}_{2} \mathrm{O}_{3}$-deionized water mixtures of concentrations up to $2.1 \%$. First, nanoparticles are placed into deionized water at the chosen concentration and then a mechanical and ultrasonic homogenization $(700 \mathrm{~W} ; 20 \mathrm{kHz})$ is performed for $2 \mathrm{~h}$. In this process, no additive substance such as surfactant or dispersant are used.

All samples prepared in this manner are stored for $24 \mathrm{~h}$. These samples are stable and no visible phase separation is observed over this period of time.

The viscosity of $\mathrm{Al}_{2} \mathrm{O}_{3}$-deionized water mixtures, for each particular concentration, is determined with a Brookfield LVDV-III Ultra Rheometer as described by Namburu et al. [45]. Viscosity measurements are performed just after nanofluid preparation and after storage for $24 \mathrm{~h}$. No significant differences between the two measurements were found.

Nanofluid Flow through a Porous Cylinder. The testing porous material is a solid cylinder (radius $3.23 \mathrm{~cm}$, length $25 \mathrm{~cm}$ ) made of polytetrafluoroethylene and containing 90 equally spaced and identical cylindrical voids (radius $1.70 \mathrm{~mm}$, length $25 \mathrm{~cm}$ ). The porosity of this porous cylinder is 0.249 .

The experimental setup consists of the test porous material, water pump, flowmeter, pressure transducer and collecting tank. The schematic diagram of this setup is shown in Figure 1.

The nanofluid $\left(\mathrm{Al}_{2} \mathrm{O}_{3}\right.$ - deionized water mixture) is circulated with a pump at different flow rates. Measurements are performed after a minimum of 15 minutes of continuums flow, to achieve steady state required to take the reading. The flow rate and the pressure drop across the porous material are recorded. During the experiments the temperature is kept constant at $25^{\circ} \mathrm{C}\left( \pm 2^{\circ} \mathrm{C}\right)$. 


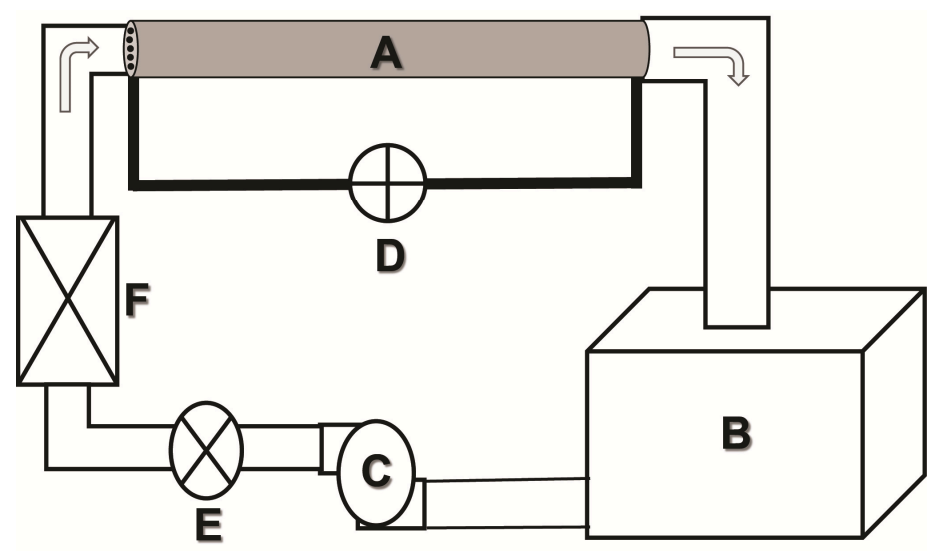

Figure 1. Schematic representation of the elements constituting the experimental setup to measure nanofluid flow rate and pressure drop ( $A$ porous cylinder, $B$ collecting tank, $C$ pump, $D$ pressure transducer, $E$ by pass regulator, $F$ flowmeter).

\section{Results}

Viscosity and Density of Nanofluids. The measured viscosities and densities of the nanofluids are presented in Figures 2 and 3 for the operating temperature of $25^{\circ} \mathrm{C}\left( \pm 2^{\circ} \mathrm{C}\right)$ and for all tested volume fractions.

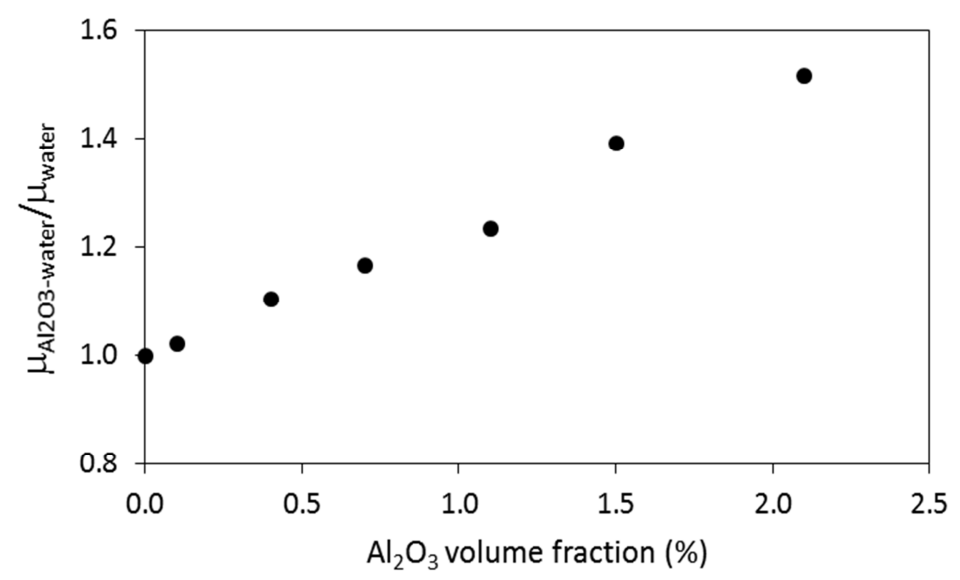

Figure 2. The ratio of $\mathrm{Al}_{2} \mathrm{O}_{3}$-deionized water mixture viscosity $\left(\mu_{\mathrm{Al} 2 \mathrm{O} 3 \text {-water }}\right)$ to deionized water viscosity ( $\mu_{\text {water }}$ ) versus $\mathrm{Al}_{2} \mathrm{O}_{3}$ volume fraction: $\mu_{\text {water }}=8.91 \times 10^{-4} \mathrm{~Pa} . \mathrm{s}$; temperature $25^{\circ} \mathrm{C}\left( \pm 2^{\circ} \mathrm{C}\right)$.

As expected, Figures 2 and 3 show that the measured viscosity and density of nanofluids increases as the nanoparticle volume fraction increases. Regression analysis is used to estimate the relationship between viscosity or density and nanoparticles volume fraction. For Figures 2, a linear and an exponential fit of data points provide the same $r^{2}$ value for regressions $\left(r^{2}=0.991\right)$. That is

$$
\begin{array}{ll}
\frac{\mu_{\mathrm{Al} 203 \text {-water }}}{\mu_{\text {water }}}=0.996+0.2474 \theta & , \mathrm{r}^{2}=0.991 \\
\frac{\mu_{\mathrm{Al} 203 \text {-water }}}{\mu_{\text {water }}}=1.007 \exp (0.2003 \theta) & , \mathrm{r}^{2}=0.991
\end{array}
$$

where $\theta$ is the volume fraction of $\mathrm{Al}_{2} \mathrm{O}_{3}$ particles. 


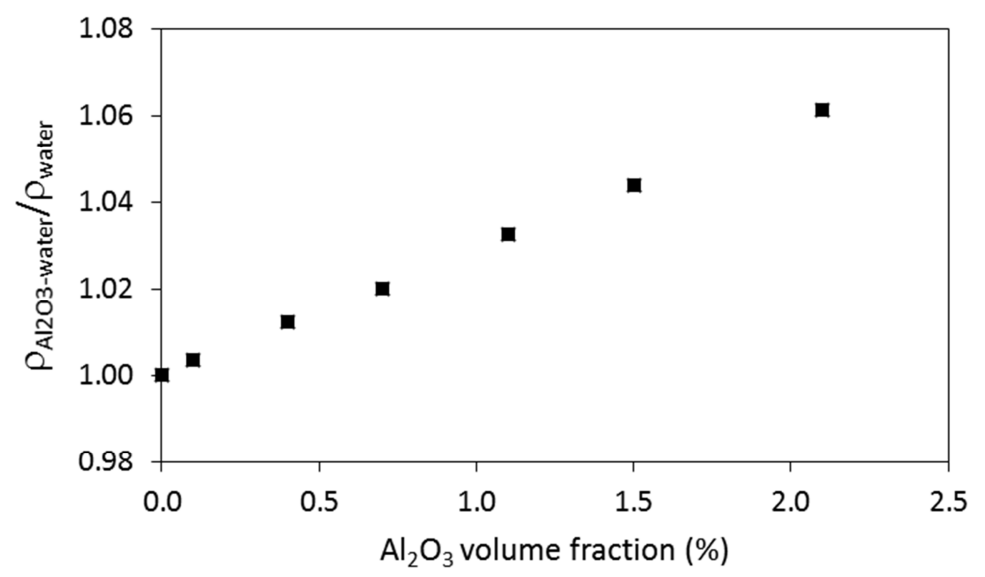

Figure 3. The ratio of $\mathrm{Al}_{2} \mathrm{O}_{3}$-deionized water mixture density ( $\rho_{\mathrm{Al} 2 \mathrm{O} 3 \text {-water }}$ ) to deionized water density ( $\left.\rho_{\text {water }}\right)$ versus $\mathrm{Al}_{2} \mathrm{O}_{3}$ volume fraction: $\rho_{\text {water }}=997.1 \mathrm{~kg} / \mathrm{m}^{3}$; temperature $25^{\circ} \mathrm{C}\left( \pm 2^{\circ} \mathrm{C}\right)$.

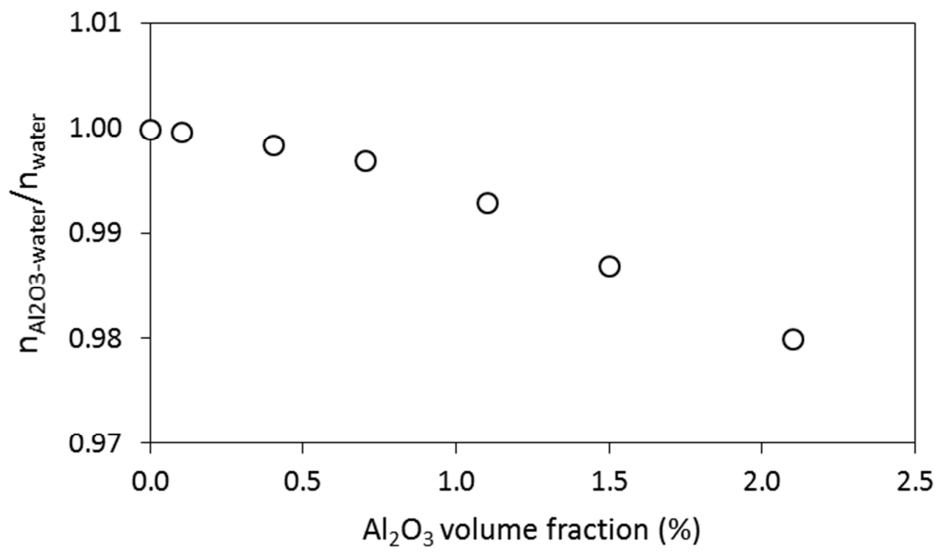

Figure 4. Power-law index n versus the volumetric fraction of nanoparticles

In the case of the data presented in Figures 3, the best fit is a line that has a slope of 0.0291, and intercept of 1.00. Or in other words

$$
\frac{\rho_{\text {Al2O3-water }}}{\rho_{\text {water }}}=1.00+0.0291 \theta \quad, r^{2}=0.997
$$

Notice that Eqs. 7 and 8 show a good agreement with the correlations available in the literature for evaluating viscosity. In fact, Eq. 7 agrees very closely with the Einstein's equation for the nanofluid viscosity (Eq. 6) and Eq. 8 is consistent with the findings of Cheng and Law [38]. Furthermore, our experimental results for the density of nanofluids (Eq. 8) are also in agreement with the theoretical prediction of mixing theory [9] (i.e., $\rho_{\mathrm{f}} / \rho_{0}=1+\left[\left(\rho_{\mathrm{s}}-\rho_{0}\right) / \rho_{0}\right] \theta$ where $\rho_{\mathrm{f}}$ is the density of nanofluid, $\rho_{0}$ is the density of the base fluid, and $\rho_{\mathrm{s}}$ is the density of the solid particles).

The power law index $n$ specifies the extent of the non-Newtonian behavior and can be obtained from the measurement of the variation of the viscosity with the shear rate. The results are depicted in Figure 4. This figure shows that a rise of nanofluid volume fraction results in a diminution of index $\mathrm{n}$. In addition, $\mathrm{Al}_{2} \mathrm{O}_{3}$ nanofluid exhibits a slight shear thinning behavior that becomes more significant with increasing volumetric fraction of nanoparticles. These results agree with the findings of [23-26].

In summary, Einstein equation (or Cheng and Law exponential approach [38]) and mixing theory correlation can predict the viscosity and the density of $\mathrm{Al}_{2} \mathrm{O}_{3}$-deionized water mixtures, respectively, within the range of nanoparticles volume fractions in this study. $\mathrm{Al}_{2} \mathrm{O}_{3}$-deionized 
water mixtures show a slight shear thinning behavior which is more pronounced for higher nanoparticles concentrations.

Permeability and Inertial Parameter. Figure 5 reports the measured pressure drop with varying flow rate for all nanofluid volume fractions studied here. These results show that, for a constant volumetric flow rate, the pressure drop increases with increasing nanofluid volume fraction, and the base fluid (deionized water) presents the lowest pressure drop.

The experimental data in Figure 5 reveals that can be adequately fitted by an equation of the type $\Delta \mathrm{p}=\mathrm{aQ} \mathrm{Q}^{\mathrm{n}}+\mathrm{bQ} \mathrm{Q}^{2}$, where $\mathrm{Q}$ is the nanofluid flow rate, and a and $\mathrm{b}$ are fitting coefficients. Regression coefficients and relevant statistics generated from best-fit experimental data sets are displayed in Table 1.

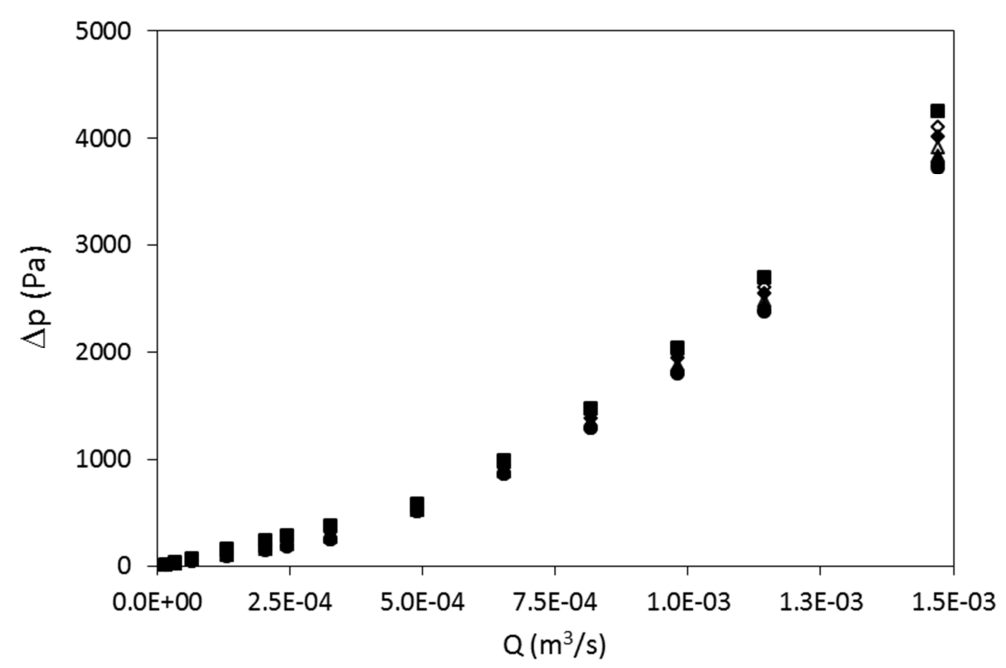

Figure 5. The pressure drop versus the nanofluid flow rate (volume fractions of $\mathrm{Al}_{2} \mathrm{O}_{3}: \bullet 0 \%, \mathrm{o}$ $0.1 \% ; \Delta 0.4 \%, \triangle 0.7 \% \diamond 1.1 \% ; \diamond 1.5 \% ;-2.1 \%)$.

The results shown in Table 1 allows us to obtain $\mathrm{K}, \mathrm{k}$ and $\beta$. Figure 6 shows the hydraulic permeability $\mathrm{K}$ for different nanoparticle volume fractions. Linear and exponential regression analysis to fit this data leads to

$$
\begin{array}{ll}
\frac{\mathrm{K}_{\text {A1203-water }}}{\mathrm{K}_{\text {water }}}=0.9865-0.1729 \theta & , \mathrm{r}^{2}=0.976 \\
\frac{\mathrm{K}_{\text {A1203-water }}}{\mathrm{K}_{\text {water }}}=0.995 \exp (-0.207 \theta) & , \mathrm{r}^{2}=0.988
\end{array}
$$

For the hydraulic permeability, contrary to previous results on viscosity (Eqs. 7 and 8), the exponential variation with $\theta$ provides a slight better correlation than the linear correlation. In both cases it is clear that, apart from the properties of porous structure, the hydraulic permeability depends on the properties of the permeant fluid [31,46,47]. 
Table 1. Polynomial coefficients $a$ and $b$ obtained from fitting experimental data, at various nanoparticle volume fractions

\begin{tabular}{|c|c|c|c|}
\hline$\theta(\%)$ & a $\left(\right.$ Pa.s $\left./ \mathrm{m}^{3}\right)$ & b $\left(\right.$ Pa.s $\left.^{2} / \mathbf{m}^{6}\right)$ & $\mathbf{r}^{2}$ \\
\hline 0.0 & 616.6 & 800.6 & 0.989 \\
\hline 0.1 & 629.2 & 805.9 & 0.991 \\
\hline 0.4 & 671.1 & 809.1 & 0.989 \\
\hline 0.7 & 733.5 & 820.2 & 0.980 \\
\hline 1.1 & 797.2 & 838.3 & 0.985 \\
\hline 1.5 & 865.4 & 845.2 & 0.990 \\
\hline 2.1 & 941.0 & 853.6 & 0.992 \\
\hline
\end{tabular}

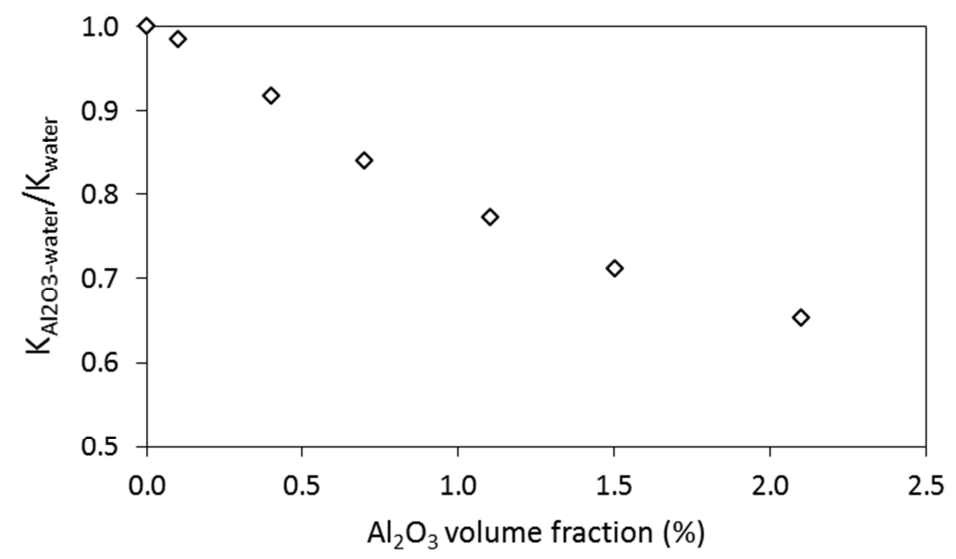

Figure 6. The ratio of hydraulic permeability for $\mathrm{Al}_{2} \mathrm{O}_{3}$-deionized water flows $\left(\mathrm{K}_{\mathrm{Al} 2 \mathrm{O} 3 \text {-water }}\right)$ to hydraulic permeability for deionized water flows $\left(\mathrm{K}_{\text {water }}\right)$ versus $\mathrm{Al}_{2} \mathrm{O}_{3}$ volume fraction: $\mathrm{K}_{\text {water }}=1.62 \times 10^{-3} \mathrm{~m}^{3} / \mathrm{Pa} \mathrm{s}$.

The intrinsic permeability and the inertial parameter are depicted in Figures 7 and 8 for all tested volume fractions of $\mathrm{Al}_{2} \mathrm{O}_{3}$. These plots reveal that $\mathrm{k}$ and $\beta$ are not dependent on the concentration of $\mathrm{Al}_{2} \mathrm{O}_{3}$ nanoparticles. Many studies have shown that the occurrence of deposition (and adhesion on surfaces and on previous deposited particles) affects the morphology of the void space and increases the resistance to fluid flow [48-50]. Therefore, Figures 7 and 8 are consistent with the fact that the void space through which the nanofluid is moving maintains its original structure. This reveals that the deposition of $\mathrm{Al}_{2} \mathrm{O}_{3}$ nanoparticles within the porous structure is absent or negligible.

Another important finding is that our results confirm those reported by Shenoy [32], based on theory, that the non-linear term of Darcy-Forchheimer is not dependent of power law index $n$ of non-Newtonian fluids. 


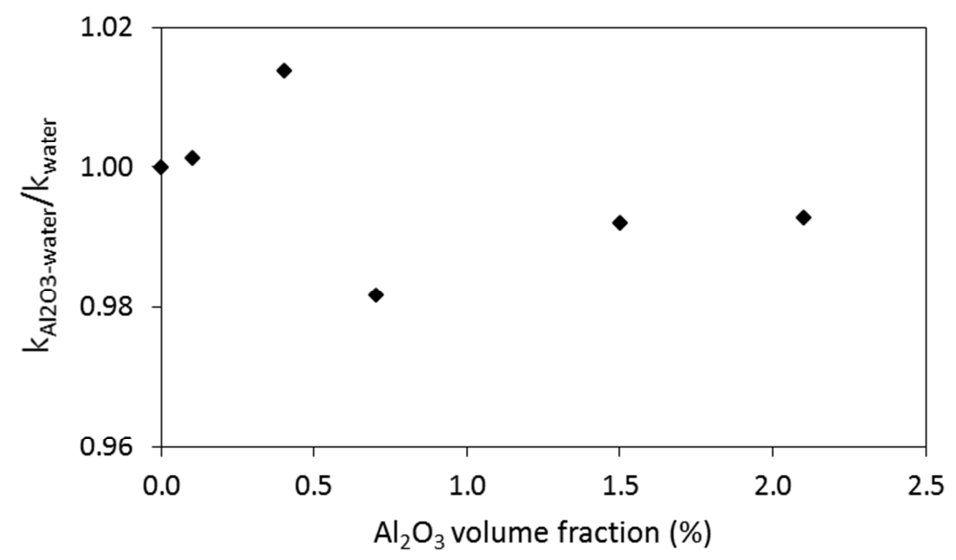

Figure 7. The ratio of intrinsic permeability for $\mathrm{Al}_{2} \mathrm{O}_{3}$-deionized water flows $\left(\mathrm{k}_{\mathrm{Al}}\right.$-O3-water $)$ to intrinsic permeability for deionized water flows ( $k_{\text {water }}$ ) versus $\mathrm{Al}_{2} \mathrm{O}_{3}$ volume fraction: $\mathrm{k}_{\mathrm{water}}=3.61 \times 10^{-7} \mathrm{~m}^{2}$.

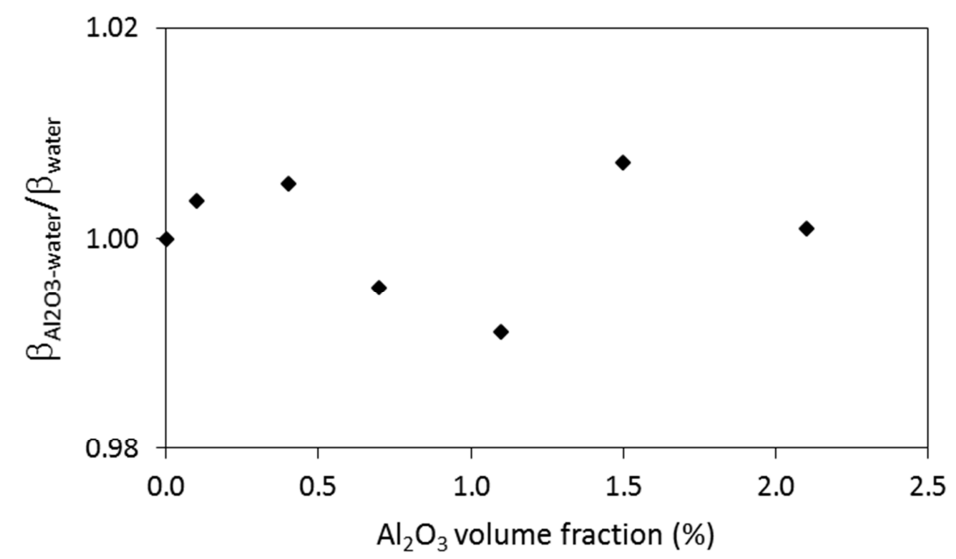

Figure 8. The ratio of inertial parameter for $\mathrm{Al}_{2} \mathrm{O}_{3}$-deionized water flows $\left(\mathrm{k}_{\mathrm{Al} 2 \mathrm{O} 3 \text {-water }}\right)$ to inertial parameter for deionized water flows $\left(\mathrm{k}_{\text {water }}\right)$ versus $\mathrm{Al}_{2} \mathrm{O}_{3}$ volume fraction: $\beta_{\text {water }}=1.93 \times 10^{-3}$.

In summary, the applicability of Darcy-Forchheimer's equation, and good predictions with it, requires not only an accurate description of both intrinsic permeability and inertial parameter but also a precise description of the physical properties of the permeant nanofluid.

\section{Conclusion}

In this study, water-based nanofluids are made by dispersing $\mathrm{Al}_{2} \mathrm{O}_{3}$ nanoparticles at different concentrations. The resulting nanofluid is then pumped into a porous cylinder at different flow rates. The results show that the viscosity and density of nanofluids increases with the volume fraction of $\mathrm{Al}_{2} \mathrm{O}_{3}$ nanoparticles. In the range of nanoparticle volume fractions investigated in this study, viscosity and density can be well predicted by the Einstein equation (or by an exponential relationship with the nanoparticles volume fraction) and by the mixing theory correlation, respectively.

The analysis performed for nanofluid flow through the porous cylinder shows that the experimental data closely match the Darcy-Forchheimer equation for power-law fluids. Our results also confirm the theoretical findings of Shenoy [32] that the non-linear term of Darcy-Forchheimer is not dependent of power law index $\mathrm{n}$ of non-Newtonian fluids.

As expected, the hydraulic permeability increases with increasing of nanoparticle volume fraction. The intrinsic permeability and the inertial parameter are independent of the volume 
fraction of $\mathrm{Al}_{2} \mathrm{O}_{3}$ nanoparticles. This suggests that the void morphology, within the porous cylinder, is not affected during nanofluid flow in this study. These results lead to the conclusion that particles deposition and adhesion on surfaces is absent, or its effect is not significant to alter the voids geometry through which the fluid is moving.

\section{References}

[1] S.K. Das, S.U.S Choi, W. Yu, T. Pradeep, Nanofluids: Science and Technology, John Wiley \& Sons, Hoboken, New Jersey, 2007.

[2] W.J. Minkowycz, E.M. Sparrow, J.P. Abraham, Nanoparticle Heat Transfer and Fluid Flow, CRC Press, Hoboken, 2012.

[3] G. Donzelli, R. Cerbino, A. Vailati, Bistable Heat Transfer in a Nanofluid, Physics Review Letters 102 (2009) 1-4.

[4] C. Kleinstreuer, J. Li, J. Koo, Microfluidics of nano-drug delivery, International Journal of Heat and Mass Transfer 51 (2008) 5590-5597.

[5] P.C. Chiang, D. S. Hung, J. W. Wang, C. S. Ho, Y. D. Yao, Engineering water dispersible FePt nanoparticles for biomedical applications, IEEE Transaction on Magnetics 43 (2007) 2445-2447.

[6] S.U.S. Choi, Z.G. Zhang, P. Keblinski, Nanofluids, in: H.S. Nalwa (Ed.), Encyclopedia of Nanoscience and Nanotechnology, American Scientific Publishers, New York, 2004, vol. 6, pp. $757-773$.

[7] J. Koo, C. Kleinstreuer, Laminar nanofluid flow in microheat-sinks, International Journal Heat Mass Transfer 48 (2005) 2652-2661.

[8] S.P. Jang, J.H. Lee, K.S. Hwang, Particle concentration and tube size dependence of viscosities of $\mathrm{Al}_{2} \mathrm{O}_{3}$-water nanofluids flowing through micro- and minitubes, Applied Physics Letters 91 (2007) 243112.

[9] B.C. Pak, Y.I. Cho, Hydrodynamic and heat transfer study of dispersed fluids with submicron metallic oxide particles, Experimental Heat Transfer 11 (1998) 151-170.

[10] W. Yu, D.M. France, J.L. Routbort, S.U.S. Choi, Review and comparison of nanofluids thermal conductivity and heat transfer enhancements, Heat Transfer Engineering 29 (2008) 32-460.

[11] A. Turgut, I. Tavman, M. Chirtoc, H.P. Schuchmann, C. Sauter, S. Tavman, Thermal conductivity and viscosity measurements of water-based $\mathrm{TiO} 2$ nanofluids, International Journal of Thermophysics 30 (2009) 1213-1226.

[12] M. Nazari, M. Ashouri, M. H. Kayhani, A. Tamayol, Experimental study of convective heat transfer of a nanofluid through a pipe filled with metal foam, International Journal of Thermal Sciences 88 (2015) 33-39.

[13] C. Pang, J.W. Lee, Y.T. Kang, Review on combined heat and mass transfer characteristics in nanofluids, International Journal of Thermal Sciences 87 (2015) 49-67.

[14] S.M.S. Murshed, C.A.N. Castro (Eds.), Nanofluids: Synthesis, Properties and Applications, Nova Science Pub., New York, 2014.

[15] L. Hendraningrat, S. Li, O. Torsæter, A coreflood investigation of nanofluid enhanced oil recovery, Journal of Petroleum Science and Engineering 111 (2013) 128-138.

[16] D. Pavlidis, D. Lathouwers. Fluid flow and heat transfer investigation of pebble bed reactors using mesh-adaptive LES, Nuclear Engineering and Design 264 (2013) 161-167. 
[17] P.L. Mills, D.J. Quiram, J.F. Ryley, Microreactor technology and process miniaturization for catalytic reactions - a perspective on recent developments and emerging technologies, Chemical Engineering Science 62 (2007) 6992-7010.

[18] P. Chandrasekaran, M. Cheralathan, V. Kumaresan, R. Velraj, Enhanced heat transfer characteristics of water based copper oxide nanofluid PCM (phase change material) in a spherical capsule during solidification for energy efficient cool thermal storage system, Energy 7 (2014) 636642.

[19] M. Hajipour, A. M. Dehkordi, Mixed-convection flow of $\mathrm{Al}_{2} \mathrm{O}_{3}-\mathrm{H}_{2} \mathrm{O}$ nanofluid in a channel partially filled with porous metal foam: experimental and numerical study, Experimental Thermal and Fluid Science 53 (2014) 49-56.

[20] A.V. Rosca, N.C. Rosca, T. Grosan, I. Pop, Non-Darcy mixed convection from a horizontal plate embedded in a nanofluid saturated porous media, International Communications in Heat and Mass Transfer 39 (2012) 1080-1085.

[21] O. Mahian, A. Kianifar, C. Kleinstreuer, M. A. Al-Nimr, I. Pop, A. Z. Sahin, S. Wongwises, A review of entropy generation in nanofluid flow, International Journal of Heat and Mass Transfer 65 (2013) 514-532.

[22] R.A. Mahdi, H.A. Mohammed, K.M. Munisamy, N.H. Saeid, Review of convection heat transfer and fluid flow in porous media with nanofluid, Renewable and Sustainable Energy Reviews 41 (2015) 715-734.

[23] Y. Ding, H. Alias, D. Wen, R.A. Williams, Heat transfer of aqueous suspensions of carbon nanotubes (CNT nanofluids), International Journal of Heat Mass Transfer 49 (2006) 240-250.

[24] P. Garg, J.L. Alvarado, C. Marsh, T.A. Carlos, D.A. Kessler, K. Annamalai, An experimental study on the effect of ultrasonication on viscosity and heat transfer performance of multi-wall carbon nanotube-based aqueous nanofluids, International Journal of Heat Mass Transfer 52 (2009) 5090-5101.

[25] H.S. Yang Hong, C.J. Choi, Study of the enhanced thermal conductivity of Fe-nanofluids, Journal of Applied Physics 97 (2005) 064311.

[26] P.C. Mishra, S. Mukherjee, S.K. Nayak, A. Panda, A brief review on viscosity of nanofluids, International Nano Letters 4 (2014) 109-120.

[27] A.F. Miguel, Non-Darcy porous media flow in no-slip and slip regimes, Thermal Science 16 (2012)167-176.

[28] M.Y. Corapcioglu, Advances in Porous Media, volume 3, Elsevier Science \& Technology, Amsterdam, 1996.

[29] A.F. Miguel, Contribution to flow characterisation through porous media, International Journal of Heat and Mass Transfer 43 (2000) 2267-2272.

[30] A.F. Miguel, A. Serrenho, On the experimental evaluation of the permeability in porous media using a gas flow method, Journal of Physics D 40 (2007) 6824-6828.

[31] A.F. Miguel, Airflow through porous screens: from theory to practical considerations, Energy and Buildings 28 (1998) 63-69.

[32] A.V. Shenoy, Darcy-Forchheimer natural, forced and mixed convection heat transfer in nonNewtonian power-law fluid saturated porous media, Transport in Porous Media 11 (1992) 219-241.

[33] A. Einstein, Eineneuebestimmung der moleküldimensionen, Annals of Physics 324 (1906) 289-306. 
[34] H.C. Brinkman, The viscosity of concentrated suspensions and solutions, Journal of Chemical Physics 20 (1952) 571.

[35] T.S. Lundgren, Slow flow through stationary random beds and suspensions of spheres, Journal of Fluid Mechanics 51 (1972) 273-299.

[36] G.K. Batchelor, The effect of Brownian motion on the bulk stress in a suspension of spherical particles, Journal of Fluid Mechanics 83 (1977) 97-117.

[37] A.L. Graham, On the viscosity of suspensions of solid spheres, Applied Scientific Research 37 (1981) 275-286.

[38] N.S. Cheng, A.W.K. Law, Exponential formula for computing effective viscosity, Powder Technology 129 (2003) 156-160.

[39] J. Avsec, M. Oblak, The calculation of thermal conductivity, viscosity and thermodynamic properties for nanofluids on the basis of statistical nanomechanics. International Journal of Heat Mass Transfer 50 (2007) 4331-4341.

[40] J. Garg, B. Poudel, M. Chiesa, J.B. Gordon, J.J. Ma, J.B. Wang, Z.F. Ren, Y.T. Kang, H. Ohtani, J. Nanda, G.H. McKinley, G. Chen, Enhanced thermal conductivity and viscosity of copper nanoparticles in ethylene glycol nanofluid, Journal of Applied Physics 103 (2008) 074301.

[41] S.M.S. Murshed, K.C. Leong, C. Yang, Thermophysical and electrokinetic properties of nanofluids-a critical review, Applied Thermal Engineering. 28 (2008) 2109-2125.

[42] D.P. Kulkarni, D.K. Das, G.A. Chukwu, Temperature dependent rheological property of copper oxide nanoparticles suspension (nanofluid), Journal for Nanoscience and Nanotechnology 6 (2006) 1150-1154.

[43] S.M. Hosseini, A.R. Moghadassi, D.E. Henneke, A new dimensionless group model for determining the viscosity of nanofluids, Journal of Thermal Analysis and Calorimetry 100 (2010) 873-877.

[44] W. Yu, D.M. France, J.L. Routbort, S.U.S. Choi, Review and Comparison of Nanofluid Thermal Conductivity and Heat Transfer Enhancements, Heat Transfer Engineering 29 (2008) 432460.

[45] P.K. Namburu, D.P. Kulkarni, D. Misra, D.K. Das, Viscosity of copper oxide nanoparticles dispersed in ethylene glycol and water mixture, Experimental Thermal and Fluid Science 32 (2007) 397-402.

[46] A. Bejan, I. Dincer, S. Lorente, A.F. Miguel, A.H. Reis, Porous and Complex Flow Structures in Modern Technologies, Springer, New York, 2004.

[47] D. Allori, G. Bartoli, A.F. Miguel, Fluid flow through macro-porous materials: friction coefficient and wind tunnel similitude criteria, International Journal of Fluid Mechanics Research 39 (2012) 136-148.

[48] A. Serrenho, A.F. Miguel, Simulation and characterization of high porosity media for aerosol particle processing, Journal of Porous Media 12 (2009) 1129-1138.

[49] A.F. Miguel, A.H. Reis, M. Aydin, Aerosol particle deposition and distribution in a bifurcating ventilation duct, Journal of Hazardous Materials 116 (2004) 249-255.

[50] A.F. Miguel, Effect of air humidity on the evolution of permeability and performance of a fibrous filter during loading with hygroscopic and non-hygroscopic particles, Journal of Aerosol Science 34 (2003) 783-799 